GRASAS Y ACEITES 70 (2)

April-June 2019, e307

ISSN-L: 0017-3495

https://doi.org/10.3989/gya.0582181

\title{
Liver and serum lipids in Wistar rats fed a novel structured lipid containing conjugated linoleic acid and conjugated linolenic acid
}

\author{
M. Shagholian ${ }^{\mathrm{a}}$, S.A.H. Goli ${ }^{\mathrm{a},}$, A. Shirvani ${ }^{\mathrm{a}}$, M.R. Agha-Ghazvini ${ }^{\mathrm{b}}$ and S. Asgary ${ }^{\mathrm{c}}$ \\ ${ }^{a}$ Department of Food Science and Technology, College of Agriculture, Isfahan University of Technology, Isfahan 84156 83111, Iran \\ ${ }^{b}$ Isfahan Center of Health Research, National Institute of Health Research, Tehran University of Medical Sciences, Tehran, Iran. \\ 'Isfahan Cardiovascular Research Center, Cardiovascular Research Institute, Isfahan University of medical Sciences, Isfahan, Iran. \\ Corresponding author: amirgoli@cc.iut.ac.ir
}

Submitted: 28 May 2018; Accepted: 19 October 2018; 18 February 2019

\begin{abstract}
SUMMARY: Conjugated linoleic acid (CLA) and conjugated linolenic acid (CLnA) have been known to have several health-promoting effects. The aim of this study was to introduce a novel structured lipid (SL) including both CLA and CLnA (cis9, trans11, cis13-18:3, punicic acid) into one triacylglycerol (TAG) molecule through enzymatic interesterification and investigate its effect on body weight, liver and serum lipids in Wistar rats. CLA oil, pomegranate seed oil (as a rich source of CLnA) and soybean oil (as a negative control) were applied as other experimental oils. The rats were fed the oils at $1500 \mathrm{mg} / \mathrm{kg}$ body weight per day via oral gavage for 45 days. Gas chromatography analysis showed that SL included CLnA and CLA in roughly equal concentrations. The in vivo study revealed that SL had the greatest effect on the reduction in liver lipid weight ( $4.65 \mathrm{~g} / 100 \mathrm{~g}$ of liver) and liver TAG (13.28 mg/g) compared to soybean oil ( $8.7 \mathrm{~g} / 100 \mathrm{~g}$ and $18.8 \mathrm{mg} / \mathrm{g}$, respectively). High density lipoprotein cholesterol (HDL-C) in the serum of rats which were fed CLA oil significantly $(\mathrm{p}<0.05)$ increased (from 0.95 to 1.14 $\mathrm{mmol} / \mathrm{l}$ ). Pomegranate seed oil reduced low density lipoprotein cholesterol (LDL-C) and total cholesterol (about $40 \%$ and $24 \%$ reduction, respectively). A remarkable TAG reduction $(\mathrm{p}<0.05)$ was observed in all treated rats.
\end{abstract}

KEYWORDS: CLA oil; Fatty acids; HDL-C; LDL-C; Pomegranate seed oil

RESUMEN: Lípidos hepáticos y séricos en ratas Wistar alimentadas con nuevos lípidos estructurados que contienen ácido linoleico conjugado y ácido linolénico conjugado. Se sabe que el ácido linoleico conjugado (CLA) y el ácido linolénico conjugado (CLnA) tienen varios efectos positivos para la salud. El objetivo de este estudio fue producir un nuevo lípido estructurado (SL) que incluye tanto CLA como CLnA (cis9, trans11, cis13-18:3, ácido púnico) en una molécula de triacilglicerol (TAG) a través de la interesterificación enzimática e investigar su efecto en el cuerpo, peso, lípidos hepáticos y séricos en ratas Wistar. El aceite de CLA, el aceite de semilla de granada (como una fuente rica de CLnA) y el aceite de soja (como control negativo) se aplicaron como otros aceites experimentales. Las ratas fueron alimentadas con los aceites a razón de $1500 \mathrm{mg} / \mathrm{kg}$ de peso corporal por día mediante sonda oral durante 45 días. El análisis por cromatografía de gases mostró que SL incluía CLnA y CLA en una concentración aproximadamente igual. El estudio in vivo reveló que SL tuvo el mayor efecto sobre la reducción del peso de lípidos hepáticos (4,65 g/100 g de hígado) y TAG hepático (13,28 mg/g) en comparación con el aceite de soja $(8,7 \mathrm{~g} / 100 \mathrm{~g}$ and $18,8 \mathrm{mg} / \mathrm{g}$, respectivamente). El colesterol de lipoproteínas de alta densidad (HDL-C) en suero de ratas que fueron alimentadas con aceite de CLA significativamente $(\mathrm{p}<0.05)$ aumentó (de 0.95 a $1.14 \mathrm{mmol} / \mathrm{l}$ ) y el aceite de semilla de granada podría reducir el colesterol de lipoproteínas de baja densidad (LDL-C) y colesterol total (aproximadamente $40 \%$ y $24 \%$ de reducción, respectivamente). Se observó una notable reducción de TAG $(\mathrm{p}<0.05)$ en todas las ratas tratadas.

PALABRAS CLAVE: Aceite de CLA; Aceite de semilla de granada; Ácidos grasos; HDL-C; LDL-C

ORCID ID: Shagholian M https://orcid.org/0000-0001-7032-6688, Goli SAH https://orcid.org/0000-0001-99108019, Shirvani A https://orcid.org/0000-0001-8395-9900, Agha-Ghazvini MR https://orcid.org/0000-0002-4445-9193, Asgary S https://orcid.org/0000-0001-7724-4802

Citation/Cómo citar este artículo: Shagholian M, Goli SAH, Shirvani A, Agha-Ghazvini MR, Asgary S. 2019. Liver and serum lipids in Wistar rats fed a novel structured lipid containing conjugated linoleic acid and conjugated linolenic acid. Grasas Aceites 70 (2), e307. https://doi.org/10.3989/gya.0582181

Copyright: 02019 CSIC. This is an open-access article distributed under the terms of the Creative Commons Attribution 4.0 International (CC BY 4.0) License. 


\section{INTRODUCTION}

The disturbance in carbohydrate and lipid metabolisms and their subsequent outcomes such as obesity, diabetes and cardiovascular disease are currently the main health problems worldwide. Increasing evidence indicates that functional lipids, in addition to their nutritional roles, could have beneficial effects on the prevention and treatment of these metabolic disorders. Conjugated linoleic acid (CLA), conjugated linolenic acid (CLnA) and gamma linolenic acid are some of the mostly widely studied functional lipid components (Lee and Lee, 2006; Rodríguez-Alcalá et al., 2017)

CLA is a general term referring to all positional and geometrical isomers of conjugated linoleic acid. The physiological impacts of CLA are mainly related to only two isomers of cis 9 , trans 11 and trans10, cis12 CLA (Gnadig et al., 2003; Park, 2009). It needs to be pointed out that naturally occurring CLA, present in foods such as meat, milk, and dairy products, mainly consists of the cis 9 , trans 11 isomer (> 80\%) (Park, 2009). In 1995, the first report regarding the ability of CLA to reduce the body fat of mice was published (Park et al., 1995). This work exhibited that the addition of 5\% CLA to dietary food significantly reduced the animal's body lipids and increased their protein and water contents. Later, it was discovered that the CLA trans 10 , cis 12 isomer could be responsible for those effects (Wahle et al., 2004; Park and Pariza, 2007). The ability of CLA to influence lipid metabolism has been attributed to some factors such as increase in lipolysis and fatty acid oxidation rate and reduction in cellular fatty acid absorption (Park and Pariza, 2007). Gilbert et al., (2011) found that trans-trans CLArich soy oil lowered liver lipids and reduced serum cholesterol and low-density lipoprotein cholesterol by 41 and $50 \%$, respectively, compared to obese rats.

Conjugated linolenic acids are a group of geometric and conformational isomers of linolenic acid in which double links are in conjugate forms. CLnA isomers could be found as the major fatty acid in the oils extracted from the special plant seeds; $\alpha$-eleostearic acid (cis 9 , trans 11 , trans $13-18: 3$ ) in bitter gourd, punicic acid (cis9, trans11, cis 1318:3) in pomegranate, catalpic acid (trans 9 , trans 11 , cis 13-18:3) in catalpa and jacaric acid (cis8, trans 10 , cis12-18:3) in jacaranda seed oils (Mine et al., 2009). Arao et al., (2004) fed the rats with a diet enriched with pomegranate seed oil (PSO) and reported that punicic acid significantly reduced the accumulation of triacylglycerols (TAG) and monounsaturated fatty acids in the liver. They reported that PSO, thanks to its high phyto-estrogen content, could prevent breast cancer and be used in dermatological anti-aging products. Yuan et al., (2009) found that CLnA and CLA could exhibit distinctive effects on body fat mass and liver triacylglycerol levels in mice.
They reported that the TAG level in the liver was significantly decreased in mice fed with punicic acid while this value significantly increased in animals fed with the CLA isomer mixture. Koba et al., (2002) compared the effect of dietary CLnA on body weight, serum and liver lipid levels with that of CLA in rats. They observed that CLnA but not CLA significantly increased serum and liver TAG concentrations.

The properties and healthful impacts of oils and fats are directly related to the type of triacylglycerols. Nevertheless, the triacylglycerol type is characterized by the type and location of fatty acids within the glycerol molecular structure (Reena et al., 2009; Farmani and Hamedi, 2006). Translocation of fatty acids within TAG can occur through a process called interesterification. A structured lipid (SL) is a TAG in which new fatty acids have been attached or have been re-structured so that the fatty acid location is changed and a new triacylglycerol structure would be synthesized (Lee and Lee, 2006). Interesterification could be applied as an approach to incorporate functional lipid components such as CLA or CLnA in a TAG backbone and consequently increase their concentration in edible fats and oils. CLA was successfully incorporated into canola oil through acidolysis as its content in produced SL was $26.6 \mathrm{~mol} \%$ after $48 \mathrm{~h}$ of reaction time (Goli et al., 2008). Adhikari et al., also produced an interesterified fat containing 5.2-6.1\% CLA using soybean oil and palm stearin as base stocks (Adhikari et al., 2012). In order to elevate the healthful effects of oils and fats, the concept of changing TAG structure and balancing the type of fatty acids has been recently advocated by nutritionists, dieticians and medical practitioners (Reena et al., 2009).

In order to obtain the health benefits of CLA and CLnA simultaneously, it is imperative and desirable to produce specific structured lipids (SLs) including both functional fatty acids in TAG structure. Therefore, the aim of this work was to synthesize a novel SL comprising of CLA and CLnA through enzymatic interesterification and attest its healthpromoting effects on the serum and liver lipids of Wistar rats.

\section{MATERIALS AND METHODS}

\subsection{Materials}

CLA oil, as a triacylglycerol molecule, containing $73.5 \%$ conjugated linoleic acid was kindly donated by Nutrition Lipid Co. (Wormerveer, Netherlands). Pomegranate seed was obtained from Neyriz Co. (Shiraz, Iran). The rhizomucor miehei lipase enzyme (RM IM) was a gift provided by Novozymes (Tehran, Iran). Wistar rats were obtained from Razi Research Institute (Tehran, Iran) and their prepared powdered food was purchased from Pars Animal Feed Co. 
(Tehran, Iran). The standard diet contained crude fat $2 \%$, crude protein $17.5 \%$, crude fiber $6.6 \%$, mineral mixture $3.5 \%$ and vitamin mixture $1 \%$. Serum cholesterol, triacylglycerols, low-density lipoprotein cholesterol (LDL-C) and high-density lipoprotein cholesterol (HDL-C) were measured on a Hitachi 902 biochemistry analyzer by commercial colorimetric kits from Pars Azmoon Co. (Tehran, Iran). Pure methyl esters of fatty acids (99.9\% purity) as standards including palmitic (16:0), stearic (18:0), oleic (18:1), linoleic (18:2), isomers of conjugated linoleic (cis9, trans 11 and trans 10 , cis 12-18:2) and conjugated linolenic acids (cis9, trans 11 , cis 13-18:3, punicic acid) were purchased from Sigma-Aldrich Chemical Co. (St Louis, MO). Triacylglycerol standards ( $\geq 99 \%$ purity) including LnLnLn (Ln: linolenic acid), LLL (L: linoleic acid), OOO (O: oleic acid), PPP (P: palmitic acid) and SSS (S: stearic acid) were obtained from Sigma-Aldrich Chemical Co. (St Louis, MO). Other triacylglycerols present in the samples were identified by Equivalent Carbon Number.

\subsection{Structured lipid production}

Pomegranate seed oil was firstly extracted from pomegranate seeds using the solvent extraction method according to Abbasi et al., (2008) with some modification. The seeds were ground, immersed in $\mathrm{n}$-hexane $(1: 2, \mathrm{w} / \mathrm{v})$ and mixed for $6 \mathrm{~h}$ under vacuum atmosphere. Finally, the extract was filtered to remove solid particles and the solvent was eliminated using a rotary vacuum evaporator. The oil was kept in amber bottles at refrigerator temperature until further analysis.

In order to produce structured lipids including CLA and CLnA, CLA oil was enzymatically interesterified with PSO, as a good source of CLnA, using the microbial lipase enzyme, RM IM lipase. To investigate the effect of the main parameter and optimize the process, the response surface methodology (RSM) was applied. The numeric factors at three levels consisted of reaction time in the range of 24-72 $\mathrm{h}$, reaction temperature in the range of $45-65^{\circ} \mathrm{C}$ and CLA content in the range of $40-60 \%$ were attested. The ratio of CLA/CLnA and free fatty acid content in the structured lipid were considered as responses (Table 1). Free fatty acid content was measured based on the AOCS method Cd 3d-63 (AOCS 2004). The ratio CLA/CLnA was determined by the quantification of CLA and CLnA in each treatment using gas chromatography as described in section 2.3.

Based on the minimum content of FFA $(2.3 \%)$ and nearly equal contents of CLA and CLnA (1:1) in the structured lipid (SL), the optimized conditions of weight ratio (CLA oil to PSO), reaction time and temperature were selected as $43 \%, 24 \mathrm{~h}$ and $56{ }^{\circ} \mathrm{C}$, respectively using RSM. In these optimized points, the reaction yield for TAG synthesis was $97.7 \%$.

TABLE 1. Treatments conducted based on RSM and obtained values for ratio of CLA:CLnA and free fatty acid (FFA) percentage in the products.

\begin{tabular}{|c|c|c|c|c|c|}
\hline Treatments (Run) & $\begin{array}{c}\text { Time } \\
\text { (h) }\end{array}$ & $\begin{array}{c}\text { Temperature } \\
\left({ }^{\circ} \mathbf{C}\right)\end{array}$ & $\begin{array}{c}\text { CLA } \\
\text { (\% substrate) }\end{array}$ & CLA:CLnA & $\%$ FFA \\
\hline 1 & 24 & 45 & 40 & 1.28 & 2.38 \\
\hline 2 & 48 & 50 & 45 & 0.86 & 2.08 \\
\hline 3 & 24 & 65 & 40 & 1.93 & 2.62 \\
\hline 4 & 72 & 45 & 60 & 1.05 & 2.15 \\
\hline 5 & 72 & 65 & 60 & 0.8 & 2.75 \\
\hline 6 & 72 & 65 & 40 & 1.54 & 2.5 \\
\hline 7 & 48 & 55 & 60 & 1.91 & 2.77 \\
\hline 8 & 72 & 55 & 50 & 1.84 & 2.58 \\
\hline 9 & 24 & 65 & 60 & 1.88 & 2.42 \\
\hline 10 & 24 & 45 & 60 & 0.85 & 2.51 \\
\hline 11 & 24 & 55 & 40 & 0.89 & 2.09 \\
\hline 12 & 24 & 45 & 50 & 0.9 & 2.33 \\
\hline 13 & 72 & 45 & 60 & 1.77 & 2.24 \\
\hline 14 & 72 & 45 & 40 & 1.87 & 1.59 \\
\hline 15 & 72 & 65 & 40 & 1.93 & 2.49 \\
\hline 16 & 24 & 65 & 60 & 0.84 & 2.23 \\
\hline 17 & 48 & 65 & 50 & 1.92 & 2.8 \\
\hline 18 & 72 & 65 & 60 & 1.9 & 2.72 \\
\hline
\end{tabular}


Accordingly, the reaction was performed to produce enough SL for further experiments. Conjugated linoleic acid oil and PSO as an enzyme substrate (43:57 $\mathrm{w} / \mathrm{w}$ ) were weighed in a $250 \mathrm{~mL}$ Erlenmeyer flask with a screw cap. The reaction was started by adding the microbial lipase enzyme (7\% by total weight of substrate). The flask containing the reaction mixture (CLA oil, PSO and lipase) was flushed by nitrogen, sealed with a stopper and incubated for $24 \mathrm{~h}$ in an orbital shaker at $200 \mathrm{rpm}$ and $56^{\circ} \mathrm{C}$.

\subsection{Fatty acids profile of CLA, pomegranate seed and SL oils}

The fatty acids profile of the oils was determined by gas chromatography (Agilent, Model $6890 \mathrm{n}$, USA) following their methyl ester preparation using the method described by Goli et al., (2008). Briefly, a 50 micro liter sample was dissolved in 1 milliliter of hexane, then 100 micro liters sodium methoxide $(0.5 \mathrm{~N})$ were added and the mixture was shaken at room temperature for $15 \mathrm{~min}$. At the end, the methylated sample was passed through anhydrous sodium sulfate to lose its moisture. A HP- 88 column $(100 \mathrm{~m} \times 250 \mu \mathrm{m} \times 0.20 \mu \mathrm{m})$ was used to separate fatty acid methyl esters. The carrier gas was nitrogen with a flow rate of $1.1 \mathrm{ml} / \mathrm{min}$. The column temperature program was first held for one minute at $150{ }^{\circ} \mathrm{C}$, then increased to $190^{\circ} \mathrm{C}$ at a rate of $5{ }^{\circ} \mathrm{C} / \mathrm{min}$, after 2 min at $190{ }^{\circ} \mathrm{C}$, the temperature was raised to $240{ }^{\circ} \mathrm{C}$ at a rate of $5^{\circ} \mathrm{C} / \mathrm{min}$, and kept at this temperature for $8 \mathrm{~min}$. The detector was flame ionization detector (FID) and the temperatures of the detector and injector were $250{ }^{\circ} \mathrm{C}$ and $150{ }^{\circ} \mathrm{C}$, respectively. The injection volume was one micro liter with a 1 to 30 split ratio.

\subsection{Triacylglycerol structure in CLA, pomegranate seed and SL oils}

Reverse-phase high pressure liquid chromatography (HPLC- Younglin, Germany) was used to determine the TAG species of pomegranate seed, CLA and SL oils. The HPLC system consisted of a dual pump (SP930D; Yonglin Anyang, Korea) with evaporative light-scattering detector (ELSD, Sedex 75; Sedere, Alfortville, France). The nebulizing gas was nitrogen set at 2.2 bar, the evaporation temperature was set at $40{ }^{\circ} \mathrm{C}$ and the gain (PM) at 11. For separation, a Nova-Pak C18 column (150 $\mathrm{mm} \times 3.9 \mathrm{~mm} \times 4 \mu \mathrm{m}$, Waters, Milford, MA, USA) was used. The column temperature was $25^{\circ} \mathrm{C}$. The elution solvent consisted of (A) acetonitrile and (B) isopropanol/hexane $(2: 1, \mathrm{v} / \mathrm{v})$. The mobile phase flow rate of $1 \mathrm{ml} / \mathrm{min}$ was selected with the following profiles; $0-44 \mathrm{~min}, 20 \% \mathrm{~B} ; 45-50 \mathrm{~min}, 46 \% \mathrm{~B}$; 51-58 min, $100 \%$ B. Each sample (5 mg) was first filtered, followed by dissolving in chloroform $(10 \mathrm{ml})$ and then $20 \mu \mathrm{L}$ were injected into the HPLC. Peak determination was made in comparison to the retention time of TAG standards and the calculation of Equivalent Carbon Number (ECN) (Mitra et al., 2010).

\subsection{Animals}

Forty male Wistar rats, weighing about 177-227 grams and 5-weeks-old at the beginning of the experiment, were housed in aluminum cages (five rats in each cage) with filter tops under controlled conditions of 12-hour light/dark cycle, $50 \pm 5 \%$ humidity and $23 \pm 2{ }^{\circ} \mathrm{C}$ temperature. The Ethics Committee of the Isfahan Cardiovascular Research Center approved the present study, and the animals were handled according to the guidelines of the Isfahan University of Medical Sciences (Isfahan, Iran) for the care and use of laboratory animals.

\subsection{Experimental design}

After a 7-day adaptation period, the rats were randomly divided into four groups, ten animals in each and weighed as initial weight. Food (standard pellet) and water were provided ad libitum. The rats were given $1500 \mathrm{mg} / \mathrm{kg}$ body weight per day via oral gavage for 45 days as follows: group 1, pomegranate seed oil; group 2, CLA oil; group 3, structured lipids and group 4, soybean oil (as a control group).

\subsection{Blood sample collection and analysis}

In order to evaluate the blood factors, blood collection was done two times; on day zero and at the end of treatment period (on the 45th day). The rats were fasted for 16 hours before sampling. The blood collection was performed by cardiac puncture under anesthesia (diethyl ether). The serum was separated by centrifuge (at $2500 \times \mathrm{g}$ for $20 \mathrm{~min}$ ) and analyzed for total cholesterol, triacylglycerol, low density lipoprotein cholesterol (LDL-C) and high density lipoprotein cholesterol (HDL-C) using biochemical test Pars Azmoon Kits (Pars Azmoon Co., Tehran) according to the colorimetric method.

\subsection{Liver lipid extraction}

At the end of the experimental period, the liver of the rats was dissected, weighed, immediately frozen and stored at $-20{ }^{\circ} \mathrm{C}$ until analysis. Total lipid was extracted by the method of Folch et al., (1975). Briefly, one gram of homogenized liver was added to a $2: 1$ solution of chloroform/methanol $(\mathrm{v} / \mathrm{v})$. The final volume was $20 \mathrm{ml}$ and it was thoroughly mixed for $20 \mathrm{~min}$. After filtration, distilled water $(4 \mathrm{ml})$ was added to the mixture and centrifuged. The lower phase was isolated and the lipid was obtained by evaporating the solvent. Commercial biochemical 
kits were used to measure the concentration of cholesterol and TAG in liver.

\subsection{Statistical analysis}

All experiments were carried out in triplicate $(n=3)$ and reported as the mean \pm SD. The data were statistically analyzed by ANOVA program in statistix 8 software. The means test was conducted using the least significant difference (LSD) test at a confidence level of $95 \%$. To evaluate significant differences between the values obtained from days zero and 45 , the t-student's test was applied.

\section{RESULTS}

\subsection{Fatty acid composition and triacylglycerol structure}

The Fatty acids profile of the oils is shown in Table 2. CLA oil contained nearly equal values of the two major isomers of CLA; cis 9 , trans 11 $(36.8 \%)$ and trans 10 , cis $12(38.5 \%)$. The predominant fatty acid in PSO was conjugated linolenic acid (cis9, trans11, cis13-18:3, CLnA), which is known as punicic acid $(77.1 \%)$, followed by linoleic $(7.9 \%)$ and oleic (7\%) acids.

After interesterification and in the structured lipid, the major fatty acids were found to be CLnA $(39.5 \%)$ followed by cis 9 , trans $11(19.4 \%)$ and trans 10 , and $\operatorname{cis} 12(19.1 \%)$ CLA isomers. With respect to fresh oils, the fatty acid composition changed in SL after lipase-catalyzed interesterification. The major fatty acids in PSO, namely punicic and linoleic acids decreased to about 39.5 and $4.7 \%$ respectively, while the CLA content reached 38.5\% in SL. The result showed that the interesterification reaction was well successful to produce a SL containing almost equal amounts of CLA (38.5\%) and CLnA (39.5\%). Generally, it could be said that the produced SL consisted of $78 \%$ fatty acids of CLA and CLnA.

The result of the interesterification reaction was also monitored by following the changes in the relative concentrations in the various TAG species of PSO and CLA oil (Table 3). Originally, PSO contained two major TAGs of $\mathrm{CnCnCn}(58.5 \%)$ and

TABLE 3. Triacylglycerol compositions (g/ $100 \mathrm{~g}$ triacylglycerols) of pomegranate seed oil, CLA oil and structured lipid.

\begin{tabular}{lccc}
\hline TAG & $\begin{array}{c}\text { Pomegranate } \\
\text { seed oil }\end{array}$ & CLA oil & $\begin{array}{c}\text { Structured } \\
\text { lipid }\end{array}$ \\
\hline CnCnCn & $58.5 \pm 0.15$ & $1.5 \pm 0.00$ & $12.9 \pm 0.15$ \\
CnCnL & $9.9 \pm 0.05$ & - & - \\
CnCnLc & - & - & $27.3 \pm 0.09$ \\
CnCnO & $17.6 \pm 0.13$ & - & - \\
CnLcLc & - & $1.1 \pm 0.01$ & $27.9 \pm 0.14$ \\
CnLO & $7.7 \pm 0.08$ & - & - \\
LcLcLc & - & $54.3 \pm 0.17$ & $18.3 \pm 0.11$ \\
LcLcO & - & $30.6 \pm 0.24$ & $8.8 \pm 0.06$ \\
LLO & $2.5 \pm 0.01$ & - & - \\
LOO & - & $8.1 \pm 0.10$ & $3.1 \pm 0.01$ \\
OOO & - & $2.1 \pm 0.03$ & $1.0 \pm 0.00$ \\
\hline
\end{tabular}

Lc: conjugated linoleic acid; $\mathrm{Cn}$ : conjugated linolenic acid; O: oleic acid; L: linoleic acid

Mean value \pm standard deviation $(n=3)$

The means test was done using least significant difference (LSD) test at a confidence level of $95 \%$.

TABLE 2. Fatty acid compositions (g/100 g total fatty acids) of CLA oil, pomegranate seed oil, structured lipid and soybean oil.

\begin{tabular}{lcccc}
\hline Fatty acids & CLA oil & Pomegranate seed oil & Structured lipid & Soybean oil \\
\hline $\mathbf{1 6 : 0}$ & $5.0 \pm 0.01$ & $3.8 \pm 0.05$ & $3.7 \pm 0.01$ & $11.3 \pm 0.03$ \\
$\mathbf{1 8 : 0}$ & $2.0 \pm 0.00$ & $2.3 \pm 0.00$ & $1.8 \pm 0.04$ & $4.4 \pm 0.00$ \\
$\mathbf{1 8 : 1} \boldsymbol{c 9}$ & $11.0 \pm 0.06$ & $7.0 \pm 0.09$ & $10.6 \pm 1.01$ & $23.1 \pm 0.11$ \\
$\mathbf{1 8 : 2} \boldsymbol{c 9}, \boldsymbol{c 1 2}$ & $1.1 \pm 0.01$ & $7.9 \pm 0.14$ & $4.7 \pm 0.07$ & $52.9 \pm 1.22$ \\
$\mathbf{1 8 : 3} \boldsymbol{c 9}, \boldsymbol{c 1 2}, \boldsymbol{c 1 5}$ & - & - & - & $5.6 \pm 0.08$ \\
$\boldsymbol{c 9}, \boldsymbol{t 1 1}, \boldsymbol{c 1 3} \mathbf{C L n A}$ & - & $77.1 \pm 0.22$ & $39.5 \pm 1.51$ & - \\
$\boldsymbol{c 9}, \boldsymbol{t 1 1} \mathbf{C L A}$ & $36.8 \pm 0.08$ & - & $19.4 \pm 0.02$ & - \\
$\boldsymbol{t 1 0}, \boldsymbol{c 1 2} \mathbf{C L A}$ & $38.5 \pm 0.10$ & - & $19.1 \pm 0.00$ & - \\
Total CLA & $75.3 \pm 0.18$ & - & $38.5 \pm 0.02$ & - \\
$\mathbf{o t h e r s}$ & $5.6 \pm 0.03$ & $1.9 \pm 0.02$ & $1.2 \pm 0.01$ & $2.6 \pm 0.01$ \\
\hline
\end{tabular}

CLA, Conjugated linoleic acid; CLnA, Conjugated linolenic acid

Mean value \pm standard deviation $(n=3)$

The means test was done using least significant difference (LSD) test at a confidence level of $95 \%$. 
$\mathrm{CnCnO}(17.6 \%)$; whereas in CLA oil, LcLcLc $(54.3 \%)$ and $\mathrm{LcLcO}(30.6 \%)$ were the abundant TAGs $(\mathrm{Cn}$ : conjugated linolenic acid, Lc: conjugated linoleic acid, O: Oleic acid,). The TAG type of oil is directly dependent on its fatty acid composition. Since the major fatty acids in PSO and CLA oil were CLnA and CLA, the predominant TAG was the homogenous TAG of $\mathrm{CnCnCn}$ and LcLcLc, respectively. Interesterification is a powerful tool for changing the quantity of existing triacylglycerol molecules and/or the emergence of new triacylglycerol molecules. After the reaction, lipase enzyme transferred fatty acids between the TAGs of PSO and CLA oil and led to a significant reduction in the homogenous TAGs of $\mathrm{CnCnCn}$ (from 58.5 to $12.9 \%$ ) and LcLcLc (from 54.3 to $18.3 \%$ ), respectively (Table 3). On the contrary, heterogeneous TAG containing mixtures of $\mathrm{Cn}$ and $\mathrm{Lc}$ such as CnLcLc $(27.9 \%)$ and $\mathrm{CnCnLc}(27.3 \%)$ were increased in SL. The structured lipid consisted of four major TAGs of CnLcLc, CnCnLc, LcLcLc and CnCnCn, which showed that the interesterification condition was suitable to produce a new oil containing CLA and CLnA in its TAG structure.

\subsection{Biochemical effects of structured lipid, pomegranate seed and CLA oils}

Body weight and food intake. The effect of different diets supplemented with CLA oil, PSO, SL and also soy bean oil on body weight gain of rats after 45 days is presented in Figure 1. A significant $(p<0.05)$ increment was observed in all groups for final weight of rats compared to the beginning of the experiment period. Although the final weight of the rats fed with CLA and SL was higher than that of PSO and soybean oil, there was no significant difference among the four treatments regarding final weight or weight gain of rats. The lowest and highest amount of food intake was administrated by the PSO and SL groups (15.13 and $15.30 \mathrm{~g} / \mathrm{d}$, respectively) even though they did not show any significant difference compared to other groups.

Serum lipid levels. The effects of the various oils fed to the rats on their blood serum composition are shown in Table 4. In terms of HDL-C, only the CLA and soybean oil groups showed significant $(\mathrm{p}<$ 0.05 ) increments after 45 days (ca. 20\% increase in both groups). However, there was no significant difference in the HDL-C levels of the different groups of rats compared to the soybean oil group on the 45th day of the experimental period.

The concentration of serum LDL-C in the rats fed pomegranate seed oil declined significantly $(\mathrm{p}<$ 0.05 ) from 0.45 to $0.27 \mathrm{mmol} / \mathrm{l}$ after 45 days. As can be seen in Table 4, the type of supplemented lipid had no significant effect on serum LDL-C in Wistar rats.

A significant $(\mathrm{p}<0.05)$ reduction (about $24 \%)$ in total cholesterol (TC) was found in the PSO group over 45 days (Table 4). At the end of the experimental period, there was no significant difference in $\mathrm{TC}$ between the treated rats in each group and the soybean oil group. The results of serum HDL-C, LDL-C and TC revealed that PSO was able to reduce total cholesterol without lowering the HDL-C level in rats.

According to Table 4, serum triacylglycerol (TAG) content in all treated rats as well as the soybean oil group decreased remarkably. The results of TAG level on 45th day showed that this parameter was unchanged in the animals fed CLA oil, PSO and SL compared to the soybean oil group.

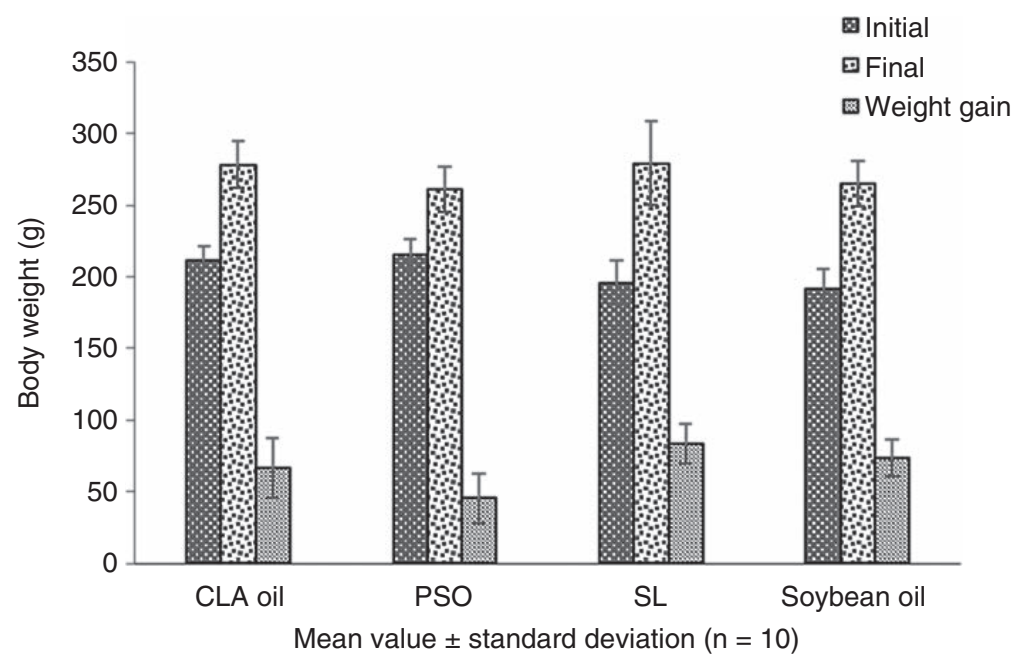

FIGURE 1. Body weight changes of Wistar rats fed with different dietary lipids for 45 days $(n=10)$. 
Liver and serum lipids in Wistar rats fed a novel structured lipid containing conjugated linoleic acid and conjugated linolenic acid $\bullet$

TABLE 4. Serum and liver lipids in Wistar rats fed with different dietary lipids for 45 days.

\begin{tabular}{|c|c|c|c|c|}
\hline \multirow[b]{2}{*}{ Parameters } & \multicolumn{4}{|c|}{ Treatment groups } \\
\hline & CLA oil & Pomegranate seed oil & Structured lipid & Soybean oil \\
\hline \multicolumn{5}{|l|}{ Serum lipids } \\
\hline \multicolumn{5}{|l|}{ HDL-C (mmol/l) } \\
\hline Day zero & $0.95 \pm 0.09^{\mathrm{b}}$ & $1.18 \pm 0.22$ & $1.06 \pm 0.16$ & $0.92 \pm 0.25^{\mathrm{b}}$ \\
\hline Day 45 & $1.14 \pm 0.13^{\mathrm{a}}$ & $1.10 \pm 0.13$ & $1.19 \pm 0.15$ & $1.10 \pm 0.17^{\mathrm{a}}$ \\
\hline \multicolumn{5}{|l|}{ LDL-C (mmol/l) } \\
\hline Day zero & $0.39 \pm 0.18$ & $0.45 \pm 0.19^{\mathrm{a}}$ & $0.34 \pm 0.26$ & $0.27 \pm 0.13$ \\
\hline Day 45 & $0.28 \pm 0.05$ & $0.27 \pm 0.05^{\mathrm{b}}$ & $0.30 \pm 0.08$ & $0.29 \pm 0.07$ \\
\hline \multicolumn{5}{|l|}{ Total cholesterol $(\mathrm{mmol} / \mathrm{l})$} \\
\hline Day zero & $1.93 \pm 0.22$ & $2.30 \pm 0.22^{\mathrm{a}}$ & $2.00 \pm 0.46$ & $1.83 \pm 0.19$ \\
\hline Day 45 & $1.82 \pm 0.24$ & $1.74 \pm 0.20^{\mathrm{b}}$ & $1.92 \pm 0.30$ & $1.80 \pm 0.30$ \\
\hline \multicolumn{5}{|l|}{ Triacylglycerol (mmol/l) } \\
\hline Day zero & $1.90 \pm 1.40^{\mathrm{a}}$ & $1.40 \pm 0.40^{\mathrm{a}}$ & $1.64 \pm 0.58^{\mathrm{a}}$ & $1.68 \pm 0.57^{\mathrm{a}}$ \\
\hline Day 45 & $0.69 \pm 0.25^{\mathrm{b}}$ & $0.62 \pm 0.16^{\mathrm{b}}$ & $0.77 \pm 0.21^{\mathrm{b}}$ & $0.83 \pm 0.23^{\mathrm{b}}$ \\
\hline \multicolumn{5}{|l|}{ Liver lipids } \\
\hline Liver lipid weight ( $\mathrm{g} / 100 \mathrm{~g}$ of liver) & $9.19 \pm 0.35^{\mathrm{A}}$ & $6.36 \pm 0.18^{\mathrm{C}}$ & $4.65 \pm 0.19^{\mathrm{D}}$ & $8.71 \pm 1.25^{\mathrm{B}}$ \\
\hline Liver triacylglycerol (mg/g) & $24.57 \pm 0.97^{\mathrm{A}}$ & $18.51 \pm 1.20^{\mathrm{B}}$ & $13.28 \pm 0.68^{\mathrm{C}}$ & $18.83 \pm 1.10^{\mathrm{B}}$ \\
\hline Liver cholesterol (mg/g) & $10.15 \pm 1.21$ & $8.76 \pm 1.84$ & $8.64 \pm 2.51$ & $8.46 \pm 1.60$ \\
\hline
\end{tabular}

Mean value \pm standard deviation $(n=10)$, The means test was done using least significant difference $(\mathrm{LSD})$ test at a confidence level of $95 \%$. The t-student's test was applied to evaluate significant differences between the values obtained from zero and day 45 .

CLA: Conjugated linolenic acid; HDL-C: High density lipoprotein cholesterol; LDL-C: Low density lipoprotein cholesterol Means followed by different small letters within a column for each parameter are significantly different $(\mathrm{P}<0.05)$

Means followed by different capital letters within a row are significantly different $(\mathrm{P}<0.05)$

Liver lipid levels. Table 4 shows the liver lipid, triacylglycerol and cholesterol contents of Wistar rats. The experiments showed that SL, containing nearly the same content of CLA and CLnA, had the most significant effect on the reduction of lipid content (from 8.71 to $4.65 \%$ ) and TAG (from 18.83 to 13.2 $\mathrm{mg} / \mathrm{g}$ ) of liver compared to soybean oil. It might be affirmed that the novel SL could decrease the accumulation of lipids in the liver. Pomegranate seed oil had no significant effect on liver triacylglycerol in rats compared to the soybean oil sample. Although PSO could reduce the weight of liver lipids significantly $(p<0.05)$, it was not as effective as the structured lipid. Moreover, in comparison to soybean oil, the liver lipid weight and TAG content increased in the rats fed the CLA oil (5.5\% and 30.4\% increment, respectively).

\section{DISCUSSION}

To the best of our knowledge, this is the first work to investigate the effect of a novel structured lipid (consisting of equal amounts of CLA and CLnA) on serum and liver lipid characteristics in a healthy animal model- Wistar rat.

Our findings on the fatty acid profile of PSO were in agreement with the results obtained by other researchers who demonstrated that the CLnA level of PSO in 25 pomegranate varieties grown in Iran was in a wide range from 31.8 to $86.6 \%$ (Fadavi et al., 2006). In another report, the amount of punicic acid was reported at about $72 \%$ Punica granatum seed oil (Miranda et al., 2009). According to Turtygin et al., (2013) the seed oil from various pomegranates contained a wide range of punicic acid from 70.24 to $89.68 \%$.

In this study, CLA oil, PSO and SL had no significant effect on the body weight of rats compared to the control. This result was in concordance with the report showing that adding $1 \%$ punicic acid and $1 \%$ CLA into the mice diet had no significant effect on final body weight (Miranda et al., 2009). It has been reported that there was no remarkable difference among the final weight of Wistar rats fed with $0.5 \%$ CLA, $0.5 \%$ CLnA and the control group over 7 weeks (Miranda et al., 2009). Moreover, the feed supplemented with pomegranate seed oil $(0.12$ and $1.2 \%$ ) showed no effect on the body weight of mice for 3 weeks (Yamasaki et al., 2006). According to Vyas et al., (2012) and Kostogrys and Pisulewski (2010), a diet containing conjugated linoleic acid had no effect on the body weight of rats. Koba et al., (2002) found that the groups fed with $1 \%$ of experimental fats; CLA, CLnA, linoleic acid and linolenic 
acid showed no significant difference in final body weight after 4 weeks. On the contrary, a significant reduction in body weight of Otsuka-Long Evans Tokushima (OLETF) rats fed 5\% punicic acid (cis9, trans 11 , cis 13$)$, not $2 \%$ was observed after 2 weeks by Arao et al., (2004).

Many epidemiological studies have reported the importance of abnormalities in LDL-C, triacylglycerol, total cholesterol and even HDL-C as risk factors for cardiovascular disease. High levels of serum cholesterol, especially the low density type known as LDL-C, are considered major risk factors for coronary heart disease (CHD); whereas high levels of the high density type (HDL-C) are recognized as beneficial in reducing CHD risk (Parto et al., 2015). According to our results, blood serum parameters (HDL-C, LDL-C, TC and TAG) were not affected by CLA oil, PSO or SL given as an oral gavage after 45 days. In terms of total cholesterol, the data was consistent with the results reported by Yuan et al., (2009). It has been reported that the concentration of serum cholesterol was significantly lower in the CLnA than in the linoleic acid group in rats (Koba et al., 2002). In another research, it was found that margarine supplemented with $0.5 \%$ CLnA and $0.5 \%$ CLA had no significant effect on the TC of mice after short (10 week) and long (18 week) periods of feeding (Franczyk-Zarów et al., 2015). Koba et al., (2002) also demonstrated how 1\% CLA exhibited a decreasing trend, although this cholesterol-lowering effect was not statistically significant against $1 \%$ linoleic acid. Interestingly, it has been reported that the total serum cholesterol of rats fed with $2.4 \%$ punicic acid was the lowest compared to the highest value obtained with a $1.2 \%$ punicic acid diet (Mukherjee et al., 2002).

Our findings on HDL-C were in agreement with the results of Yuan et al., (2009) who did not find any effect of supplementation with $1 \%$ punicic acid for 6 weeks on serum HDL-C in mice. Moreover, this author showed that feeding diets supplemented with $1 \%$ purified punicic acid did not exhibit a significant effect on HDL-C in hamsters. Furthermore, it was reported that margarine supplemented with $0.5 \%$ punicic acid (cis 9 , trans 11 , cis $13-18: 3$ ), 0.5\% CLA and linolenic acid had no effect on HDL-C serum in apoE/LDLR-/- mice after short (10 weeks) and long (18 weeks) periods (Franczyk-Zarów et al., 2015).

With respect to LDL-C, Mukherjee et al., [24] reported that the diet containing 0.6 (59.5 mg.dl-1) and 2.4\% (56.5 mg.dl-1) punicic acid could significantly lower LDL-C while the rats fed with $1.2 \%$ punicic acid showed a higher level of LDL-C (100.1 mg.dl-1) compared to the control (66.5 mg.dl-1). In agreement with our work, another researcher found that dietary CLA treatments had no significant effects on the TC, HDL-C and LDL-C in Wistar rats (Kostogrys and Pisulewski, 2010).
Similar results for serum triacylglycerol were also reported by other researchers (Mukherjee et al., 2002; Kostogrys and Pisulewski, 2010) who found TAG was decreased in rats fed CLA-supplemented diet. However, Yuan et al., (2009) obtained no significant differences in TAG, TC, HDL-C or LDL-C levels in serum among the groups fed with corn oil (as control), punicic acid and CLA. These results are in good accordance with the study showing that there was not any remarkable effect on TAG, TC, HDL-C serum in mice fed with CLnA, CLA and linoleic acid compared to control group after 10 weeks. On the contrary, Koba et al., (2002) observed that the concentration of serum TAG increased 2.5fold in rats fed CLnA compared to the animals fed linoleic acid, linolenic acid or CLA.

Liver is the central organ responsible for triglyceride and cholesterol metabolisms and plays a key role in many physiological and patho-physiological states involving lipid metabolism. Since lipid metabolism in liver dictates the crucial steps in atherosclerosis, non-alcoholic fatty liver disease (NAFLD), diabetes, MS, insulin sensitivity, lipotoxicity and many other systemic diseases, monitoring the changes in liver lipids is important (Hassan et al., 2014). Regarding liver lipids, SL had the greatest effects on reduction in its weight and triacylglycerols and the maximum amount of these parameters belonged to the rats fed with CLA oil. PSO could reduce the amount of mentioned values in Wistar rats compared to soybean oil after 45 days. Similar results have been reported by other researchers (Arao et al., 2004; Koba et al., 2007), who found that the levels of liver TAG decreased by feeding a diet supplemented with $9 \%$ safflower oil and $1 \%$ PSO in Otsuka-Long Evans Tokushima (OLETF) rats for 2 weeks and a diet with pomegranate seed oil in ICR CD1 mice for 4 weeks, respectively. However, Koba et al., (2002) reported that CLnA increased liver TAG concentration two-fold compared to linoleic acid, linolenic acid and conjugated linoleic acid. Previous studies on mice showed that CLA could cause significant hepatomegaly accompanied by an accumulation of lipids in the liver (Yuan et al., 2009; Wendel et al., 2008). The obtained findings in the present work (difference among the groups) could be mainly attributed to the fatty acid composition of used lipids. CLA oil with $75.3 \%$ isomers of cis 9 , trans 11 and trans 10 , cis 12 accumulated lipid and triacylglycerol in the liver while PSO containing 77.1\% punicic acid (CLnA) significantly reduced liver lipid and TAG. However, SL, consisting of $38.5 \%$ CLA and $39.5 \%$ CLnA, had a significant reductive effect on lipid and TAG levels of liver which might prove that the combination of both CLA and CLnA oils in one lipid could have a synergistic effect for reducing the lipid and TAG levels of liver. It is possible, however, that high concentrations of CLnA and CLA had a negative impact on liver TAG. No significant 
difference in liver cholesterol level was obtained among the four groups, which is consistent with the results of other papers (Yuan et al., 2009; Kostogrys and Pisulewski, 2010).

\section{CONCLUSIONS}

The aim of the present study was to investigate the positive effects of both conjugated linolenic and conjugated linoleic acid in a novel structured lipid (SL) on blood serum and liver lipids in healthy Wistar rats. The lipid had a potent effect mainly on reducing liver lipid and triacylglycerol compared to the other fed lipids. Moreover, the structured lipid showed a minimum total cholesterol concentration in liver. The findings revealed that SL could be considered as a healthful lipid specifically on liver lipid composition and be useful for patients with nonalcoholic fatty liver disease (NAFLID), although pharmacokinetic tests on its absorption, toxicity and optimal dose are necessary. It is worth noting that further research is needed to examine the effect of this lipid on the blood serum along with some beneficial and supplementary analysis such as RT-PCR, FASN, SREBP1c, SCD1, PPARs and western blot technique to confirm the data. Moreover, safety concerns regarding the use of SL in humans would need further investigation with a better experimental designs that will clarify the mechanisms of SL's activities.

\section{REFERENCES}

Abbasi H, Rezaei K, Rashidi L. 2008. Extraction of essential oils from the seeds of pomegranate using organic solvents and supercritical $\mathrm{CO}_{2}$. J. Am. Oil Chem. Soc. 85, 83-89. https://doi.org/10.1007/s11746-007-1158-x

Adhikari P, Hu P, Yafei Z. 2012. Oxidative stabilities of enzymatically Interesterified fats containing conjugated linoleic acid. J. Am. Oil Chem. Soc. 89, 1961-1970. https://doi. org/10.1007/s11746-012-2096-9

Arao K, Wang YM, Inoue N, Hirata J, Cha JY, Nagao K, Yanagita T. 2004. Dietary effect of pomegranate seed oil rich in 9cis, 11trans, 13cis conjugated linolenic acid on lipid metabolism in obese, hyperlipidemic OLETF rats. Lipids Health and Dis. 24, 1-7. https://doi.org/10.1186/1476-511X-3-24

Fadavi A, Barzegar M, Azizi MH. 2006. Determination of fatty acids and total lipid content in oilseed of 25 pomegranates varieties grown in Iran. J. Food Compos. Anal. 19, 676-680. https://doi.org/10.1016/j.jfca.2004.09.002

Farmani J, Hamedi M. 2006. Application of palm olein in the production of zero-trans Iranian vanaspati through enzymatic interesterification. Eur. J. Lipid Sci. Technol. 108, 636-643. https://doi.org/10.1002/ejlt.200600025

Folch J, Lees M, Sloane-Stanley GH. 1975. A simple method for the isolation and purification of total lipids from animal tissue. J. Biol. Chem. 226, 497-509.

Franczyk-Zarów M, Czyzynska I, Drahun A, Maslak E, Chłopicki S, Kostogrys RB. 2015. Margarine supplemented with conjugated linolenic acid (CLnA) has no effect on atherosclerosis but alleviates the liver steatosis and affects the expression of lipid metabolism genes in apoE/LDLR/- mice. Eur. J. Lipid Sci. Technol. 117, 589-600. https://doi. org/10.1002/ejlt.201400253

Gilbert W, Gadang V, Proctor A, Jain V, Devareddy L. 2011. Trans-trans conjugated linoleic acid enriched soybean oil reduces fatty liver and lowers serum cholesterol in obese zucker rats. Lipids 46, 961-968. https://doi.org/10.1007/ s11745-011-3585-6

Gnadig S, Xue Y, Berdeaux O, Cheardigni JM, Sebedio JL. 2003. Conjugated linoleic acid (CLA) as a functional ingredient, in Saadholm, TM, Saarela M. (Eds.) Functional Dairy Products. CRC Press, Cambridge, 263-297. ISBN: 1855735849.

Goli AH, Kadivar M, Keramat J, Fazilati M. 2008. Conjugated linoleic acid (CLA) production and lipase lipasecatalyzed interesterification of purified CLA with canola oil. Eur. $J$. Lipid Sci. Technol. 110, 400-404. https://doi.org/10.1002/ ejlt.200700267

Hassan W, Ding L, Gao RY, Liu J, Shang J. 2014. Interleukin-6 signal transduction and its role in hepatic lipid metabolic disorders. Cytokine 66, 133-142. https://doi.org/10.1016/j. cyto.2013.12.017

Koba K, Akahoshi A, Yamasaki M, Tanaka K, Yamada K, Iwata T, Kamegai T, Tsutsumi K, Sugano M. 2002. Dietary conjugated linolenic acid in relation to CLA differently modifies body fat mass and serum and liver lipid levels in rats. Lipids 37, 343-350. https://doi.org/10.1007/ s11745-002-0901-7

Koba K, Imamura J, Akashoshi A, Kohno-Murase J, Nishizono S, Iwabuchi M, Tanaka K, Sugano M. 2007. Genetically modified rapeseed oil containing cis-9, trans-11, cis-13-octadecatrienoic acid affects body fat mass and lipid metabolism in mice. J. Agric. Food Chem. 55, 3741-3748. https:// doi.org/10.1021/jf063264z

Kostogrys RB, Pisulewski PM. 2010. Conjugated linoleic acid decreased serum triacyloglycerol and changed fatty acid composition in rat's liver. J. Animal Feed Sci. 19, 484 494. https://doi.org/10.22358/jafs/66313/2010

Lee JH, Lee KT. 2006. Structured lipids production, in: Akoh CC (Ed.) Handbook of Functional Lipids. CRC Press, London, 489-513. ISBN: 9780849321627

Mine Y, Miyashita K, Shahidi F. 2009. Nutrigenomics and proteomics in health and disease: food factors and gene interactions Wiley-blackwell.

Miranda J, Fernández-Quintela A, Macarulla MT, Churruca I, García C, Rodríguez VM, Simón E, Portillo MP. 2009. A comparison between CLNA and CLA effects on body fat, serum parameters and liver composition. J. Physiol. Biochem. 65, 25-32. https://doi.org/10.1007/BF03165966

Mitra K, Choi W, Lee T. 2010. Production and characterization of $\alpha$-linolenic acid enriched structured lipids from lipasecatalyzed interesterification. Food Sci. Biotechnol. 19, 7-62. https://doi.org/10.1007/s10068-010-0008-z

Mukherjee C, Bhattacharyya S, Bhattacharyya D. 2002. Dietary effects of punicic acid on the composition and peroxidation of rat plasma lipid. J. Oleo Sci. 51, 513-522. https:// doi.org/10.5650/jos. 51.513

Official methods and recommended practices of the AOCS. 2004. AOCS Press, Champaign.

Park Y, Albright KJ, Liu W, Cook ME, Pariza MW. 1995. Dietary conjugated linoleic acid (CLA) reduces body fat content and isomers of CLA are incorporated into phospholipid fraction. In: Institute of Food Technologist Annual Meeting: Book of Abstracts.

Park Y, Pariza MW. 2007. Mechanisms of body fat modulation by conjugated linoleic acid (CLA). Food Res. Int. 40, 311-323. https://doi.org/10.1016/j.foodres.2006.11.002

Park Y. 2009. Conjugated linoleic acid (CLA): Good or bad trans fat?. J. Food Comp. Anal. 22S, S4-S12. https://doi. org/10.1016/j.jfca.2008.12.002

Parto P, Lavie CJ, Swift D, Sui X. 2015. The role of cardiorespiratory fitness on plasma lipid levels. Expert Rev. Cardiovasc. Ther. 13, 1177-1183. https://doi.org/10.1586/1 4779072.2015.1092384

Reena MB, Reddy SRY, Lokesh BR. 2009. Changes in triacylglycerol molecular species and thermal properties of blended and interesterified mixtures of coconut oil or palm oil with rice bran oil or sesame oil. Eur. J. Lipid Sci. Technol. 111, 346-357. https://doi.org/10.1002/ejlt.200800065

Rodríguez-Alcalá LM, Castro-Gómez MP, Pimentel LL, Fontecha J. 2017. Milk fat components with potential 
anticancer activity-A review. Biosci. Rep. 37. https://doi. org/10.1042/BSR20170705

Turtygin AV, Deineka VI, Deineka LA. 2013. Determination of the triglyceride composition of pomegranate seed oil by reversed-phase HPLC and spectrophotometry. J. Anal. Chem. 68, 558-563. https://doi.org/10.1134/S1061934813060142

Vyas D, Kadegowda AKG, Erdman RA. 2012. Dietary conjugated linoleic acid and hepatic steatosis: species-specific effects on liver and adipose lipid metabolism and gene expression. J. Nutr. Metab. 2012, 1-13. https://doi. org/10.1155/2012/932928

Wahle KWJ, Heys SD, Rotondo D. 2004. Conjugated linoleic acid: are they beneficial or detrimental to health?. Prog. Lipid Res. 43, 553-587.
Wendel AA, Purushotham A, Liu LF, Belury MA. 2008. Conjugated linoleic acid fails to worsen insulin resistance but induces hepatic steatosis in the presence of leptin in ob/ ob mice. J. Lipid Res. 49, 98-106. https://doi.org/10.1194/ jlr.M700195-JLR200

Yamasaki M, Kitagawa T, Koyanagi N, Chujo H, Maeda $\mathrm{H}$, Kohno-Murase J, Imamura J, Tachibana H, Yamada K. 2006. Dietary effect of pomegranate seed oil on immune function and lipid metabolism in mice. Nutr. 22, 54-59. https://doi.org/10.1016/j.nut.2005.03.009

Yuan G, Haiyan S, Sinclair J. 2009. Effects of conjugated linolenic acid and conjugated linoleic acid on lipid metabolism in mice. Eur. J. Lipid Sci. Technol. 111, 537-545. https://doi. org/10.1002/ejlt.200800200 